\title{
Assay of the Requisite of the Metallic Corrosion in Crude Oils
}

\author{
Aluvihara Suresh ${ }^{1}$ and Premachandra J agath $\mathrm{K}^{2 *}$ \\ ${ }^{1}$ Department of Chemical and Process Engineering, \\ University of Peradeniya, Sri Lanka \\ ${ }^{2}$ Department of Chemical and Process Engineering, \\ University of Moratuwa, Sri Lanka \\ *Corresponding author: J agath K Premachandra, \\ Department of Chemical and Process Engineering, \\ University of Moratuwa, Katubedda, Sri Lanka
}

Received: December 06, 2018; Accepted: February 15, 2019; Published: February 22, 2019

\begin{abstract}
Crude oil is a mixture of hydrocarbons with some trace compounds including corrosive causing agents. Corrosion is a severe consequence regarding the industry of crude oil refining. Using the general definition of the formations of metal sulfides, oxides or hydroxides on the metal surface and the process is occurred by the corrosive properties of crude oils. The scope of this research was to investigate the contributions of corrosive properties of both Murban and Das Blend crude oils on the corrosion rates of seven different types of ferrous metals, which are obligatory in the crude oil refining industry. The sulfur contents, mercaptans contents, acidities and salt contents of both crude oils were tested by following standard methodologies and instruments. The elemental composition of each metal coupon was tested by the XRF detector. A batch of similar sized metal coupons was prepared and those metal coupons were immersed separately in both crude oils in homogeneous way. After 15, 30 and 45 days from the immersion the corrosion rates of each type of metal were determined by the relative weight loss method with the aid of a microscopic analysis. The decayed ferrous and copper concentrations in crude oil samples were tested by the Atomic Absorption Spectroscopy (AAS) and the variations of the initial hardness of such metal coupons due to the corrosion were tested as confirmation stages of the formation of the corrosion. There were found some relatively lower corrosion rates from stainless steels with respect to both crude oils among other metals, formations of different types of corrosion compounds, higher ferrous and copper concentrations in some of crude oil samples and slight reductions of the initial hardness of most of metal coupons due to the corrosion as the head most results of the aforesaid research.
\end{abstract}

Keywords: Crude oils; Corrosive properties; Ferrous metals; Weight loss; Corrosion rates

\section{Introduction}

Crude oil is a predominantly occurred as a mixture of hydrocarbons since having some trace chemical compounds that gives various behaviors to the relevant crude oils including the corrosive behaviors. The corrosive phenomenon is usually found regarding several industries, which are having some vast applications in ferrous metals. Crude oil refining industry is a foremost industry that considered the corrosive matters as an adverse effect for most of devices such as storage tanks, distillation columns, transportation tubes and heat exchangers [1-3]. In terms of material engineering the corrosion can be defined as the formations of metal oxides, sulfides or hydroxides on the metal surface and also a process of either chemical or electrochemical as a result of the interaction between the metal and surrounding environment in other words [1-5].

Basically regarding the metals this would be an oxidation process and it shows quite various appearances due to the formation conditions such as galvanic corrosion, pitting corrosion and stress corrosion. The metal need to expose any environment which is containing both water and oxygen or some oxidation agent that stronger than $\mathrm{Fe}^{2+}$ also these processes are braced by the salts and organic acids presence in the medium. Some important investigations about the effect of such corrosive compounds on the on the corrosion rates of different types of metals and their changes regarding some important properties have been done in vast ranges of researches [1-9]. The investigation of the stability and efficacy of stainless steels against the corrosive environment when comparing with other ferrous metals, the contributions of the selected corrosive properties of crude oils on the corrosion rates of different ferrous metals, the qualitative analysis of the usually forming corrosion compounds on the metal surfaces due to the effects of crude oils and the variations of some important surface properties of metals such as the hardness were the prime outlooks of the current research.

\section{Materials and Methods}

\section{Materials}

There were selected seven different types of ferrous metals which are having pivotal applications in the process of crude oil refining by recovering various tasks as given in the below.

- Carbon Steel (High) - Transportation tubes, storage tanks

- Carbon Steel (Medium) - Transportation tubes, storage tanks

- Carbon Steel (Mild Steel) - Heat exchanges

- 410-MN: 1.8 420-MN: 2.8 (Stainless Steel) - Crude distillation unit 

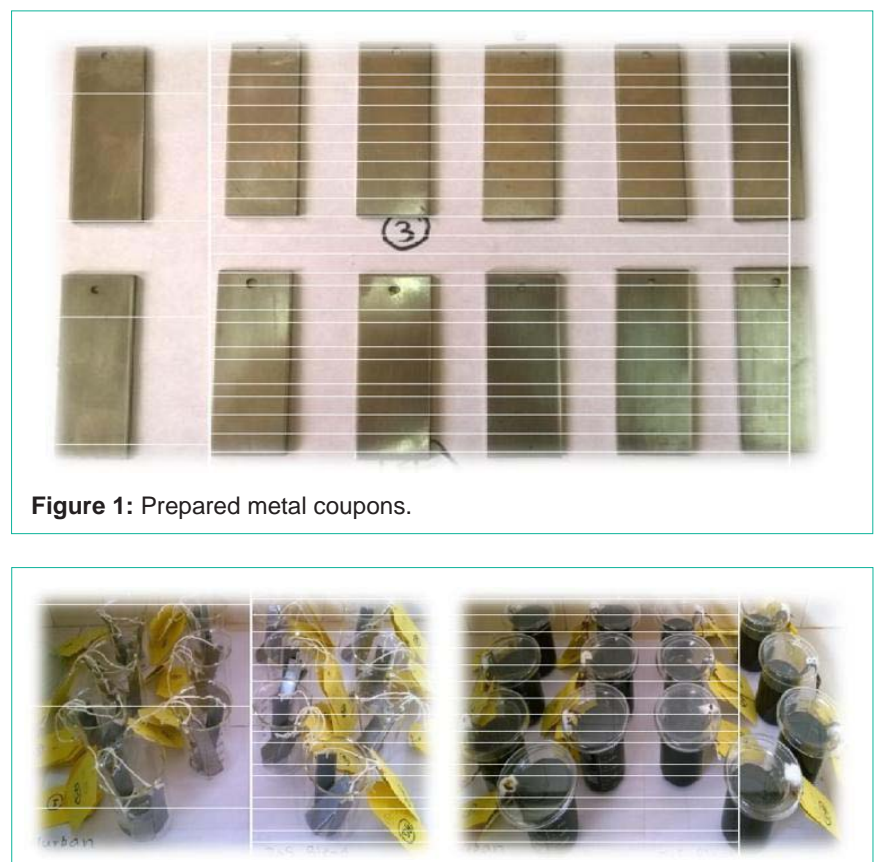

Figure 2: Metal coupons and the setup of samples.

- 410-MN: 1.7 420-MN: 1.7 (Stainless Steel) - Crude distillation unit

- 321-MN: 1.4 304-MN: 1.9 (Stainless Steel) - Crude distillation unit

\section{- Monel 400 - Heat exchangers}

There were used two different types of crude oils frequently used in most of crude oil refineries. Murban and Das Blend are two different types of crude oils since Das Blend is known as a "sour" crude oil because of the high sulfur content of such crude oil and Murban is known as a prevalent crude oil [2]. Both Murban and Das Blend crude oils are having wide ranges of applications at around the world.

\section{Methods}

The chemical compositions of stainless steels, carbon steels and Monel were tested by the XRF detractor. According to the working principles of XRF detector there were given the readings for most of composite elements including all of metallic elements, a few of non metals excluding carbon as a percentage.

According to the literature review there were selected some specific corrosive properties of both Murban and Das Blend crude oils to investigate the impact of such properties on the corrosion rates of above named metals. Therefore, the elemental sulfur contents,
Mercaptans contents, acidities and salt contents of both Murban and Das Blend crude oils were tested by well defined standard methods and instruments as given in the description in Table 1.

A set of similar sized metal coupons was prepared in equal dimensions from seven different types of metals as six metal c oupons from each type of metal as shown in the Figure 1.

The prepared metal coupons were dipped separately in both Murban and Das Blend crude oils according to the metal type as three homogeneous metal coupons in one crude oil container as shown in the Figure 2.

After 15 days from the dipping one metal coupon was taken out from each crude oil container and the corrosion rates of those metal coupons were determined by the relatively weight loss method as explained the mathematical expression and terms below [10].

$\mathrm{CR}=\mathrm{W} * \mathrm{k} /(\mathrm{D} * \mathrm{~A} * \mathrm{t})$

Where;

$\mathrm{W}=$ Weight loss in grams

$\mathrm{k}=$ Constant $(22,300)$

$\mathrm{D}=$ Metal density in $\mathrm{g} / \mathrm{cm}^{3}$

$\mathrm{A}=$ Area of metal piece $\left(\mathrm{inch}^{2}\right)$

$\mathrm{t}=$ Time (days)

$\mathrm{CR}=$ Corrosion rate of metal piece

The corroded metal surfaces were observed under the 400X lens of a laboratory optical microscope and the corroded metal surfaces were cleaned by using sand papers and isooctane to determine the weight losses of such metal coupons. Then the same procedure was repeated again twice for another two sets of immersed metal coupons in order of after 30 and 45 days from the immersion and the average corrosion rates of each type of metal were determined with respect to both Murban and Das Blend crude oils.

According to the qualitative analysis of the formed corrosion compounds on the surfaces of metal coupons the microscopic analysis stage was performed. In this stage the appearances of each metal coupon before the immersion in crude oils and the corroded surface of each metal coupon were observed by the $400 \mathrm{X}$ lens of a laboratory optical microscope and some specific appearances of such corrosion compounds were identified.

The decayed ferrous concentrations and decayed copper concentrations from interacted metal coupons were investigated in each crude oil sample because of the necessity of the clarification for the observed invisible weight loss of some metal coupons during the determination of the corrosion rates by the weight loss

Table 1: Standard test methods for the analysis of corrosive properties of crude oils.

\begin{tabular}{|l|l|l|}
\hline Property & Method & Readings \\
\hline Sulfur content & Directly used to the XRF analyzer. & Direct reading \\
\hline Acidity & Each sample was dissolved in a mixture of toluene and isopropyl and titrated with potassium hydroxide. & End point \\
\hline Mercaptans content & Each sample was dissolved in sodium acetate and titrated with silver nitrate. & End point \\
\hline Salt content & Each sample was dissolved in organic solvent and exposed to the cell of analyzer. \\
\hline
\end{tabular}


method. According to the analysis of dissolved metals in crude oil samples there were analyzed the copper concentrations in crude oil samples which were interacted with Monel metal and the dissolved ferrous concentrations of crude oil samples which were interacted with stainless steels and carbon steels by the Atomic Absorption Spectroscopy (AAS). In the sample preparation $1 \mathrm{ml}$ of each crude oil sample was diluted with $9 \mathrm{ml}$ of 2-proponol and filtered before sending to the suction of the instrument.

As a confirmation stage of the formation of the corrosion on the surface and based on the investigation of the surface property changes the variations of the initial hardness of metal coupons due to the corrosion were tested by the Vicker's hardness tester. According to the instructions regarding the Vicker's hardness tester the hardness of at least three points of each metal coupon were tested at once and the average numerical values were interpreted as the

hardness. The initial hardness and the hardness after corroded of each metal coupon were the important measurements to determine the variation of the initial hardness.

\section{Results and Discussion}

According to the obtained results of the XRF detector the elemental chemical compositions of stainless steels, carbon steels and Monel metal have been given in the Table 1 .

The above results emphasized relatively higher amounts of ferrous present in carbon steels, intermediate ferrous amounts present in stainless steels and trace amount of ferrous present in Monel metal since it was rich in copper and nickel. Usually stainless steels were composed with a trace or intermediate amounts of some other metals such as nickel and chromium that based on some advanced purposes which are given in the below $[1,4,5]$.

- Enhancement of the stress and hardness

- $\quad$ Reduce the tendency of the corrosion

In the theoretical explanation the combination of both nickel and chromium able to create a self corrosive protection layer on the metal surface itself against the corrosive environment at certain composition typically at $12 \%$ of chromium with sufficient amount of nickel as well $[1,3]$.

According to the experiments regarding the corrosive properties of both crude oils the obtained results for each property have been shortlisted in the (Table 2).

The obtained results for the acidities of both crude oils Das Blend crude oil was composed higher amount of organic acids than the Murban crude oil. According to the natural formation the crude oils may be composed with some organic acids also defined as "naphthenic acids" which is having a general formula of "RCOOH"

Table 2: Corrosive properties of crude oils.

\begin{tabular}{|l|c|c|}
\hline Property & Murban & Das Blend \\
\hline Sulfur content (Wt. \%) & 0.758 & 1.135 \\
\hline Salt content (ptb) & 4.4 & 3.6 \\
\hline Acidity $(\mathrm{mg} \mathrm{KOH} / \mathrm{g})$ & 0.01 & 0.02 \\
\hline Mercaptans content $(\mathrm{ppm})$ & 25 & 56 \\
\hline
\end{tabular}

also known as a corrosive property of crude oils [2,9]. The general reactions of the causing of metallic corrosion due to the organic acids have been given in the below.

$$
\begin{aligned}
& \mathrm{FeS}+2 \mathrm{RCOOH} \rightarrow \mathrm{Fe}(\mathrm{COOR})_{2}+\mathrm{H}_{2} \mathrm{~S} \ldots \ldots \ldots . .(2) \\
& \mathrm{Fe}+2 \mathrm{RCOOH} \rightarrow \mathrm{Fe}(\mathrm{RCOO})_{2}+\mathrm{H}_{2} \ldots \ldots \ldots \ldots . . .(3) \\
& \mathrm{Fe}(\mathrm{COOR})_{2}+\mathrm{H}_{2} \mathrm{~S} \rightarrow \mathrm{FeS}+2 \mathrm{RCOOH} \ldots \ldots \ldots . .(4)
\end{aligned}
$$

According to the obtained results for the salt contents in both crude oils Murban crude oil was composed relatively higher amount of salts than Das Blend crude oil. Especially with the natural occurrence crude oils may be consisted with $\mathrm{MgCl}_{2}, \mathrm{CaCl}_{2}$ and $\mathrm{NaCl}$ and the summation of such halides is known as the total salt content of such crude oil [7]. When increasing the temperature of the system approximately $100^{\circ} \mathrm{C}$ these salts tend to be broken into $\mathrm{HCl}$ molecules according to the chemical reaction that given in the below.

$$
\mathrm{CaCl}_{2}+\mathrm{H}_{2} \mathrm{O} \rightarrow \mathrm{CaO}+2 \mathrm{HCl}
$$

Since these $\mathrm{HCl}$ molecules are not showing any corrosive property in the gas phase and these $\mathrm{HCl}$ molecules tend to be reacted with the moisture and water presence in the crude oils when the system is approaching to some lower temperatures and formed the hydrochloric acids and hydrogen sulfides a the results [7]. These compounds are highly prone on the metallic corrosion. FeS is a dominant corrosion compound that formed under these processes as explained in the chemical reactions below.

$$
\begin{aligned}
& \mathrm{FeCl}_{2}+\mathrm{H}_{2} \mathrm{~S} \rightarrow \mathrm{FeS}+2 \mathrm{HCl} . \\
& \mathrm{HCl}+\mathrm{Fe} \rightarrow \mathrm{FeCl}_{2}+\mathrm{H}_{2} \ldots .
\end{aligned}
$$

According to the elemental sulfur contents and Mercaptans contents in both crude oils Das Blend was composed higher amounts of both elemental sulfur and Mercaptans contents than the Murban crude oil. Crude oils may be usually consisted with elemental sulfur and active sulfur compounds such as Mercaptans, thiophenes, sulfoxides and hydrogen sulfides also most of them are corrosive compounds because of the presence of a fraction or an active functional group with these compounds such as the formula of Mercaptans is "RSH". The process of corrosion due to the active sulfur compounds is known as the "sulfidation" and the corrosion process due to the elemental sulfur is known as the "localized corrosion". These processes are highly depended on the temperature of the systems and the typical temperatures for the proper progress of "sulfidation is about $230^{\circ} \mathrm{C}$ and approximately $80^{\circ} \mathrm{C}$ for the process of "localized corrosion" $[2,6,8]$. The general chemical reactions for the above processes have been given in the below.

$$
\begin{aligned}
& \mathrm{S} 8(\mathrm{~s})+8 \mathrm{H}_{2} \mathrm{O}(\mathrm{l}) \rightarrow 6 \mathrm{H}_{2} \mathrm{~S}(\mathrm{aq})+2 \mathrm{H}_{2} \mathrm{SO}_{4} \ldots \ldots \ldots(8) \\
& 8 \mathrm{Fe}+\mathrm{S} 8 \rightarrow 8 \mathrm{FeS} \ldots \ldots \ldots \ldots \ldots \ldots \ldots \ldots \ldots \ldots \ldots \ldots \ldots \ldots . . . \ldots \ldots \ldots \ldots \ldots \ldots \ldots \ldots \ldots \ldots
\end{aligned}
$$

By referring the compositions of corrosive properties of both crude oils it can be concluded that the Das Blend was ahead regarding the elemental sulfur content, Mercaptans content and organic acids content also behind according to the salt content when comparing with Murban crude oil.

The determined average corrosion rates of metal types with respect to both Murban and Das Blend crude oils have been interpreted in the (Figure 3). 


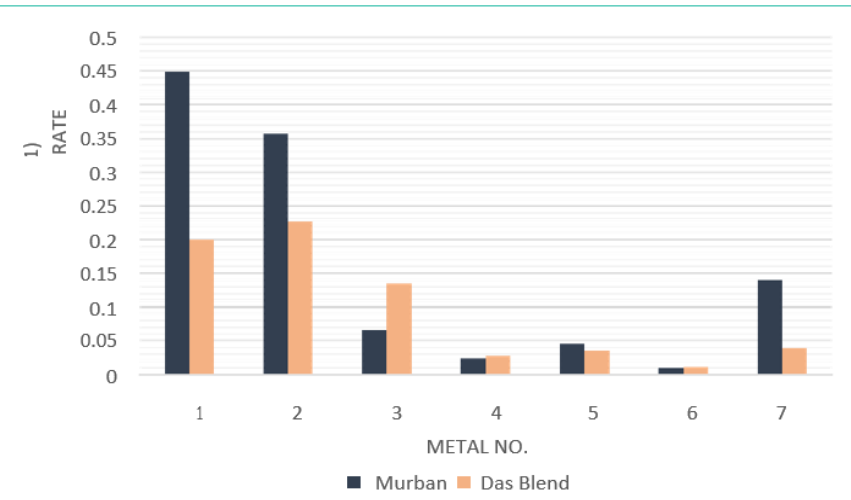

Figure 3: Average corrosion rates of metal coupons in both crude oils.

The above results showed the relatively higher corrosion rates from carbon steels in both crude oils, relatively lower corrosion rates from stainless steels in both crude oils and intermediate corrosion rates from Monel metal in both crude oils. 321-MN: 1.4 304-MN: 1.9 (Stainless Steel) showed the least corrosion rates among all other metals with respect to both Murban and Das Blend crude oils. When referring the chemical composition of 321-MN: 1.4 304-MN: 1.9 (Stainless Steel) mainly it was composed $\sim 18 \%$ of chromium and $\sim 8 \%$ of nickel. According to the theory behind the self corrosive protection film of stainless steels when composed with $12 \%$ of chromium with sufficient amount of nickel the observed results provided good enough evidences to prove the theoretical concept well [1,3-5]. When comparing the corrosion rates of other two types of stainless steel 410-MN: 1.7420 - MN: 1.7 (Stainless Steel) showed higher corrosion rates in both crude oils since it was composed $\sim 12 \%$ of chromium although lack of nickel and 410-MN: 1.8 420-MN: 2.8 (Stainless Steel) showed some kind of lower corrosion rates in both crude oils since it was composed with $\sim 11 \%$ of chromium and $\sim 0.2 \%$ of nickel. Altogether these observations there can be concluded that the optimal performances of corrosive protection film can be expected at about the recommend compositions of both nickel and chromium $[1,4,5]$.

When comparing with the corrosion rates of metals with respect to each crude oil four types of metals showed their higher corrosion rates in Murban crude oils while other three types of metals were showing their higher corrosion rates in Das Blend crude oil since Das Blend crude oil was rich in trice sulfur, Mercaptans and organic acid contents except the salt content. However the "sulfidation" and "localized corrosion" processes are extremely depended on the temperature conditions $[2,8]$. The experiments were conducted under the room temperature. Therefore, it cannot be expected proper progress regarding the elemental sulfur and Mercaptans. According to the remaining results there can be concluded that the progress of salts in the cause of metallic corrosion is stronger than the progress of organic acids on the formation of metallic corrosion because Murban was rich in salts since Das Blend was rich in organic acids.

The variations of the corrosion rates of metal coupons with the exposure time against both Murban and Das Blend crude oils have been shown in order of (Figures 4,5).

The both distributions showed some similar sequence in the variations of the corrosion rates of metal coupons with the exposure time independently with the crude oils. The obtained results

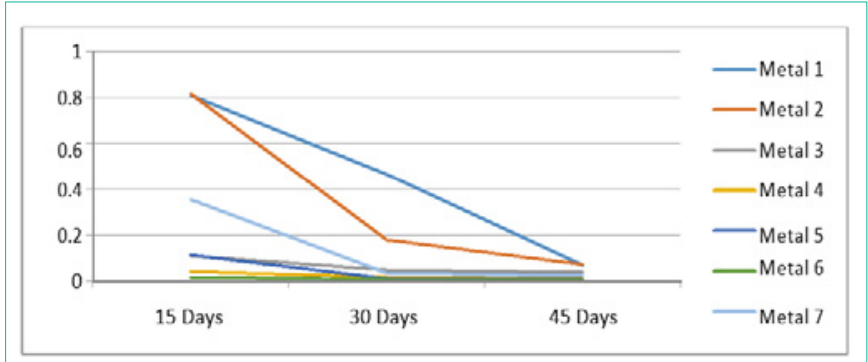

Figure 4: Deviations of the corrosion rates of metal coupons with the exposure time against the Murban crude oil.

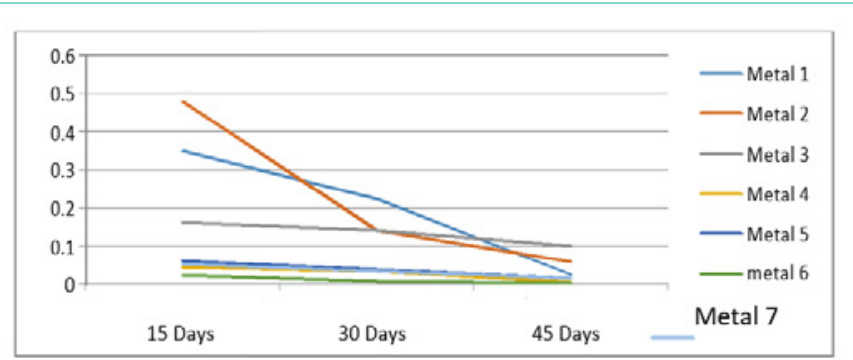

Figure 5: Deviations of the corrosion rates of metal coupons with the exposure time against the Das Blend crude oil.

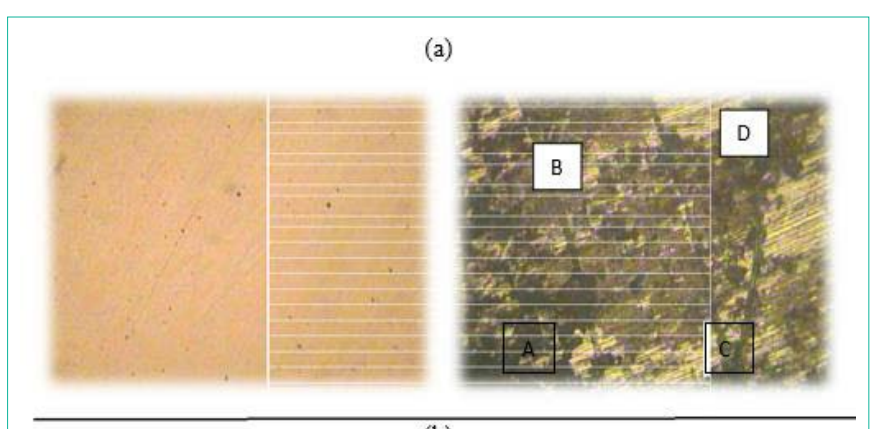

(b)
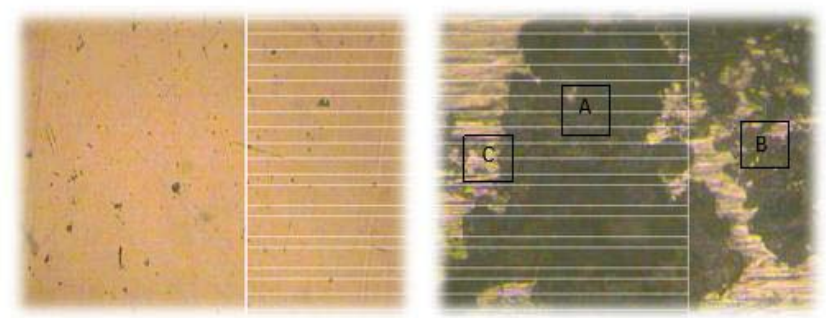

Figure 6: (a) Corroded sur face of carbon steel (mild steel) in Murban and (b) corroded surface of 410-MN: 1.7 420- MN: 1.7 (stainless steel) in Mu rban.

interpreted and prove $\mathrm{d}$ the inversely proportional relationship between the corrosion rate and the exposure time of the mathematical relationship of the weight loss method [10].

The highlighted observations of the microscopic analysis have been shown in the Figure 6.

The predominant observations have been shortlisted with the visible appearances in the below.

A - Black colored patches 
Table 3: Visible appearances of corrosion compounds.

\begin{tabular}{|l|l|l|}
\hline Compound & Appearances & Observations \\
\hline FeS & $\begin{array}{l}\text { Black, brownish black, } \\
\text { property of powder, pitting, } \\
\text { cracks }\end{array}$ & $\begin{array}{l}\text { Observed most of features } \\
\text { in each metal piece. }\end{array}$ \\
\hline $\mathrm{Fe}_{2} \mathrm{O}_{3}$ & Rusty color & Observed rarely. \\
\hline $\mathrm{CuS}$ & Dark indigo/ dark blue & Unable to specify. \\
\hline
\end{tabular}

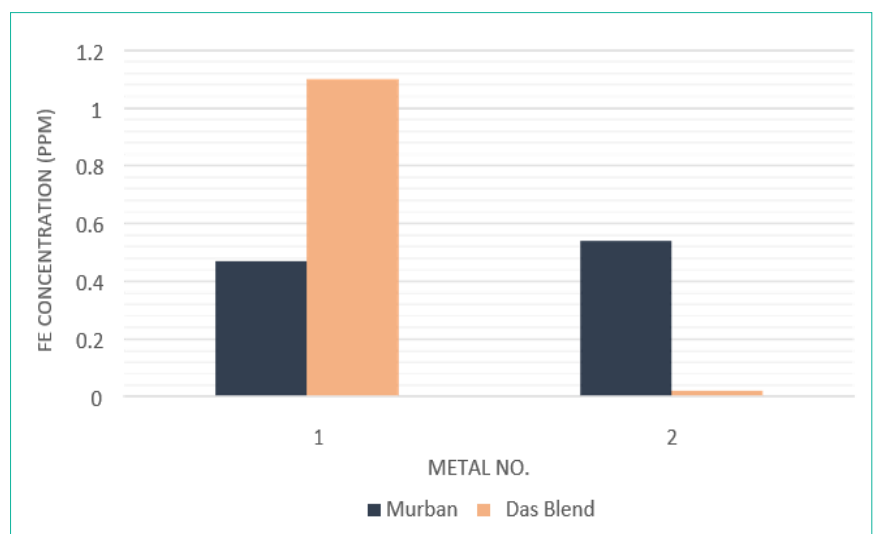

Figure 7: Ferrous concentrations in crude oil samples.

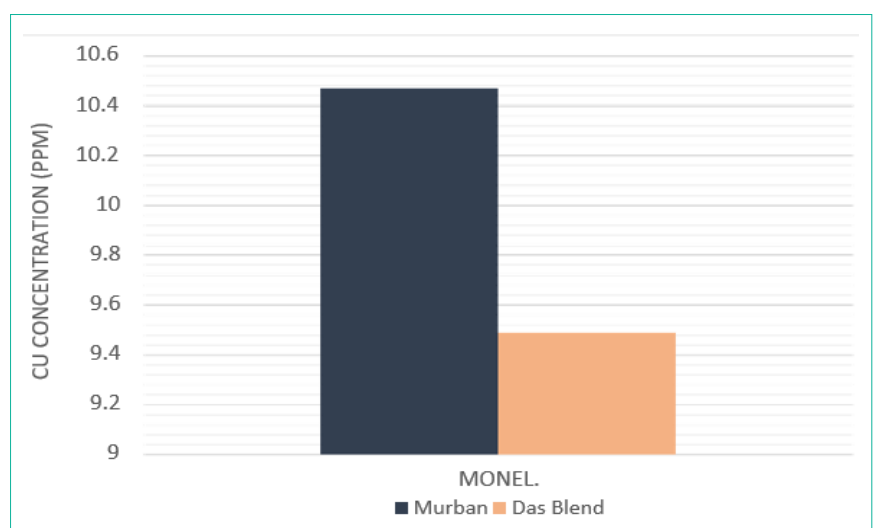

Figure 8: Copper concentrations in crude oil samples.
B - Rusty colored patches
C - Some cracks and cavities
D - Cavities

The identifications of such microscopic observations were based on the visible appearances foremost the color and surface deformations $[1,3,5]$. Some important observations have been explained and suggested some results in the (Table 3).

According to the above observations and references there can be concluded the formation of $\mathrm{FeS}$ as the corrosive compounds in most of metals, rarely formed the $\mathrm{Fe}_{2} \mathrm{O}_{3}$, formed corrosion cracks and pitting corrosion regarding most of stainless steels and the formation of CuS regarding the Monel metal although impossible to distinguish only having visible appearances and need some advanced compositional analysis forever.

Based on the results of the Atomic Absorption Spectroscopic (AAS) analysis results the decayed ferrous concentrations and decayed copper concentrations into crude oil samples from metal

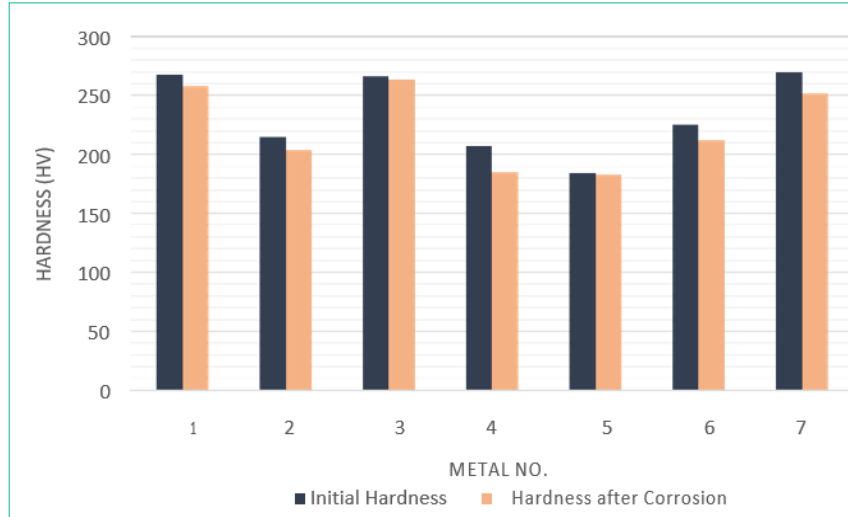

Figure 9: Variations of the hardness of metal coupons against the Murban crude oil.

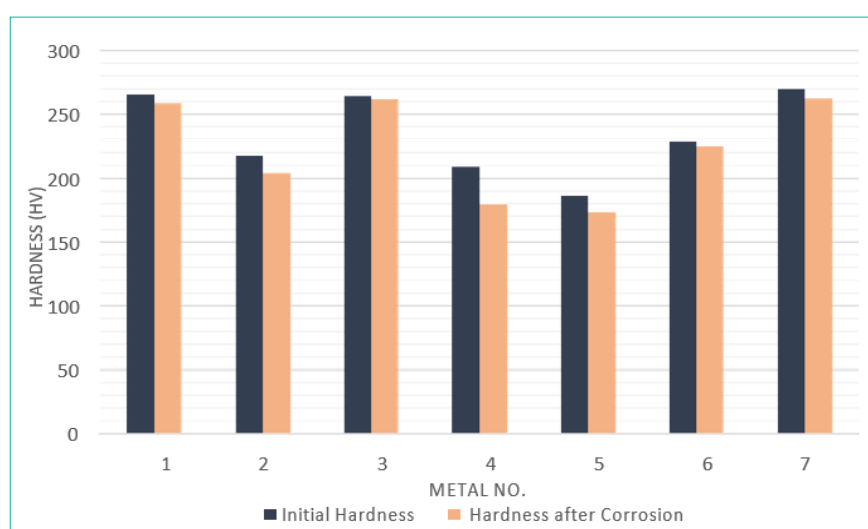

Figure 10: Variations of the hardness of metal coupons against the Das Blend crude oil.

coupons have been interpreted in order of (Figure 7,8).

The decayed ferrous concentration chart showed only higher decayed concentrations form the carbon steel (high) and carbon steel (medium) since no any decayed concentration was found in any crude oil sample that exposed to carbon steel (mild steel) or any type of stainless steels while finding some significant decayed concentrations of copper from Monel metal into both Murban and Das Blend crude oils. According to the observed results for the decayed metal concentrations the observations of the invisible weight loss of metal coupons can be explained as after formations of the corrosion on the metal surfaces such newly formed metallic compounds tend to be removed from the remained metal surface due to the attractive and repulsive forces between successive electrons and protons $[1,3,5]$. Therefore, some amount of metals may be decayed and the metallic surface may be destructed when causing the metallic corrosion.

The variations of the initial hardness of metal coupons due to the corrosion in both Murban and Das Blend crude oils have been shown in order of (Figure 9,10).

Above results showed the deductions of the initial hardness of each metal coupon with respect to both Murban and Das Blend crude oils. After the formation of the metallic corrosion the corrosion compounds tend to be removed from the metallic surfaces due to the effect of repulsive and attractive forces in between successive electrons and the protons of contributed atoms while generating 
unstable conditions on the metal surfaces $[1,3,5]$. Therefore, it can be reached to a suggestion that the hardness deductions were happened due to the formations of the metallic corrosions on the surfaces of metal coupons.

\section{Conclusion}

The obtained results showed the relatively lower corrosion rates form trice of stainless steels while carbon steels and Monel were showing relatively higher corrosion rates related to both Murban and Das Blend crude oils. The least corrosion rates were observed form 321-MN: $1.4304-\mathrm{MN}$ : 1.9 (Stainless Steel) with respect to both Murban and Das Blend crude oils. According to the microscopic analysis inceptively observed the formation of FeS in most of metals and corrosion cracks and pitting corrosion simultaneous to the typical corrosion peculiarly in case of the stainless steels. Some higher ferrous concentrations were observed in crude oil samples, which were exposed to carbon steels and lack of any ferrous amount in crude oil samples, which were exposed to stainless steels. In addition some significant copper concentrations were observed from crude oil samples which were exposed to the Monel metal. Finally a slight reduction of the initial hardness was found in each metal coupon after the formation of the corrosive compounds on the metal surface itself.

\section{Acknowledgement}

The great assistance and contributions of the supervisor, technical support of the technical officers and everybody those who has obligated us in any way will be admired by the author.

\section{References}

1. Khana OP. Materials Science and Metallurgy, New Delhi: Dhanpet Rai and Sons publication. 2009.

2. Fahim MA, Alsahhaf TA, Elkilani A. Fundamentals of Petroleum Refining, Amsterdam: Radarweg Press. 2010.

3. Calister WD. An Introduction of Materials Science and Engineering, New York: John Wiley \& Sons, Inc. 2003.

4. Davis ME, Davis RJ. Fundamentals of Chemical Reaction Engineering, New York: McGraw-Hill. 2003

5. Singh R. Introduction to Basic Manufacturing Process and Engineering Workshop, New Delhi: New Age International Publication. 2006.

6. Bolton W. ( $2^{\text {nd }}$ Ed.), Engineering Materials Technology, London: B. H Newnes Limited. 1994.

7. Badmos AY, Ajimotokan HA and Emmanuel EO. Corrosion in Petroleum Pipelines. 2009; 36-40.

8. Speight JG. ( $3^{\text {rd }}$ Ed.). The Chemistry and Technology of Petroleum, New York: Marcel Dekke. 1999.

9. Afaf GA. Thesis, University of Khartoum. 2007.

10. Oparaodu KO, Okpokwasili GC. Comparison of Percentage Weight Loss and Corrosion Rate Trends in Different Metal Coupons from two Soil Environments. 2014; 243-249.
Austin Chem Eng - Volume 6 Issue 1 - 2019

ISSN : 2381-8905 | www.austinpublishinggroup.com

Premachandra et al. (C) All rights are reserved
Citation: Suresh A and Premachandra Jagath K. Assay of the Requisite of the Metallic Corrosion in Crude Oils. Austin Chem Eng. 2019; 6(1): 1063. 